\title{
Undifferentiated carcinoma of the oropharynx: a human papillomavirus-associated tumor with a favorable prognosis
}

\author{
Danielle H Carpenter, Samir K El-Mofty and James S Lewis Jr \\ Department of Pathology and Immunology, Division of Anatomic and Molecular Pathology, Washington \\ University, St Louis, MO, USA
}

\begin{abstract}
Undifferentiated carcinoma (undifferentiated carcinoma, nasopharyngeal type, or lymphoepithelial carcinoma) is an uncommon and histologically distinct tumor in the oropharynx, which in Western countries, has been clearly shown not to harbor Epstein Barr virus (EBV). We sought to analyze these tumors for human papillomavirus (HPV) and to examine their clinical outcomes. All cases of oropharyngeal carcinoma diagnosed as 'undifferentiated' or 'lymphoepithelial' were retrieved from the department files at Barnes-Jewish Hospital. After consensus review by all three study pathologists, 16 were found to have diagnostic histological features and to lack distinguishing characteristics of other oropharyngeal cancers. Immunohistochemistry for p16 and p53 and in-situ hybridization for HPV and EBV encoded small RNA were performed. p16-positive but HPV in situ hybridization-negative cases were analyzed by polymerase chain reaction for high-risk HPV types. The results were correlated with pathological findings and clinical follow up. There were 16 patients. The average age was 59.2 years, 14 patients (88\%) were smokers, and $13(81 \%)$ had nodal metastases. In all, 14 cases (88\%) were p16 positive and $15(94 \%)$ were HPV positive by in situ hybridization and/or polymerase chain reaction. All cases were negative for EBV, and p53 was overexpressed in five (33\%), four of which were HPV positive. Disease recurred in only three patients and two of these died with disease at 38 and 136 months, respectively. Three year overall, disease-free, and disease-specific survival rates were 54,78 , and $100 \%$, respectively. In summary, in our patient population, the majority of oropharyngeal undifferentiated carcinomas harbor transcriptionally active HPV but not EBV. Almost all overexpress p16, and few have p53 overexpression. Disease-specific survival is comparable to published rates for other HPV-related oropharyngeal squamous cell carcinoma variants and is better than that of HPV-negative carcinomas.

Modern Pathology (2011) 24, 1306-1312; doi:10.1038/modpathol.2011.87; published online 13 May 2011
\end{abstract}

Keywords: human papillomavirus; lymphoepithelial; lymphoepithelioma; p16; undifferentiated

In the head and neck, undifferentiated carcinoma (also known as lymphoepithelial carcinoma or lymphoepithelioma) has historically been most frequently found in the nasopharynx. Nasopharyngeal undifferentiated carcinoma has a strong etiologic relationship with Epstein Barr virus (EBV), ${ }^{1}$ the tumor is distinctly radiosensitive, ${ }^{2,3}$ and, despite the undifferentiated appearance of the tumor cells histologically, the prognosis is relatively favorable. ${ }^{3}$ Tumors with these identical morphological features

Correspondence: Dr JS Lewis Jr, MD, Department of Pathology and Immunology, Washington University School of Medicine, $660 \mathrm{~S}$. Euclid Ave., Campus Box 8118, St Louis, MO 63110, USA. E-mail: jlewis@path.wustl.edu

Received 21 December 2010; revised 8 February 2011; accepted 16 February 2011; published online 13 May 2011 can also occur outside of the nasopharynx. The most common anatomic subsites are the oropharyn $\mathrm{x}^{4}$ and major salivary glands, ${ }^{5,6}$ but they can also occur in other sites. ${ }^{7-9}$ The oropharynx anatomically extends from the plane of the hard palate superiorly to the plane of the hyoid bone infereriorly. It is separated from the oral cavity by the junction of the soft and hard palate superiorly, the line of the circumvallate papillae inferiorly, and the anterior pillars of the fauces laterally. It includes the base of tongue ('lingual tonsil') and bilateral palatine tonsils. It is unique from the oral cavity in both its normal tissues and in the tumor types that develop there. Undifferentiated carcinomas, although rare in the oropharynx, are exceedingly rare in the oral cavity proper. Non-nasopharyngeal undifferentiated carcinoma is usually associated with EBV in 
endemic areas such as Southeast Asia, ${ }^{6,10}$ but in Western countries and most other areas of the world, almost all of the cases are EBV negative. ${ }^{11,12,7}$

Oropharyngeal squamous cell carcinoma is frequently associated with transcriptionally active high-risk human papillomavirus (HPV). HPV-related tumors typically have a distinctive non-keratinizing morphology, ${ }^{13-15}$ show strong p16 protein expression, ${ }^{16}$ and have lower rates of p53 mutation ${ }^{17}$ than most other head and neck squamous cell carcinoma. The prognosis for p16-positive oropharyngeal squamous cell carcinoma is very good and much better than for tumors which are p16 negative. ${ }^{16,18,19}$ Squamous cell carcinomas with biologically and clinically relevant HPV are largely limited to the oropharynx among head and neck sites; however, occasional examples outside of the oropharynx have been demonstrated. Tumors of the oral cavity are clearly different, the vast majority being lacking transcriptionally active HPV.

Just like in the uterine cervix, ${ }^{20-22}$ a number of histological variants of squamous cell carcinoma of the oropharynx, such as basaloid squamous cell carcinoma, ${ }^{23}$ adenosquamous carcinoma ${ }^{24}$ and papillary squamous cell carcinoma ${ }^{25}$ are HPV-related. Indeed, in the oropharynx, transcriptionally active HPV has been identified in the majority of papillary and basaloid squamous cell carcinoma. ${ }^{25,26}$ In a recent study, HPV has also been demonstrated in oropharyngeal lymphoepithelial carcinomas. ${ }^{4} \mathrm{Re}-$ gardless of their morphology, HPV-related squamous cell carcinoma variants appear to have a good prognosis, essentially the same as for typical oropharyngeal HPV-related non-keratinizing squamous cell carcinoma. ${ }^{23}$

The purpose of this study was to determine the prevalence of HPV in undifferentiated carcinoma of the oropharynx, to characterize the immunohistochemical profiles of these tumors, and to determine patient outcomes.

\section{Materials and methods}

\section{Case Identification}

The surgical pathology department files of BarnesJewish Hospital/Washington University were electronically searched from for the terms 'undifferentiated' and 'lymphoepithelial' and the anatomic subsite 'oropharynx.' Cases were reviewed by all three study pathologists (DHC, SEM, and JSL) using the WHO definition/features for undifferentiatedtype nasopharyngeal carcinoma (Figure 1) including solid sheets, irregular islands, dyscohesive sheets,
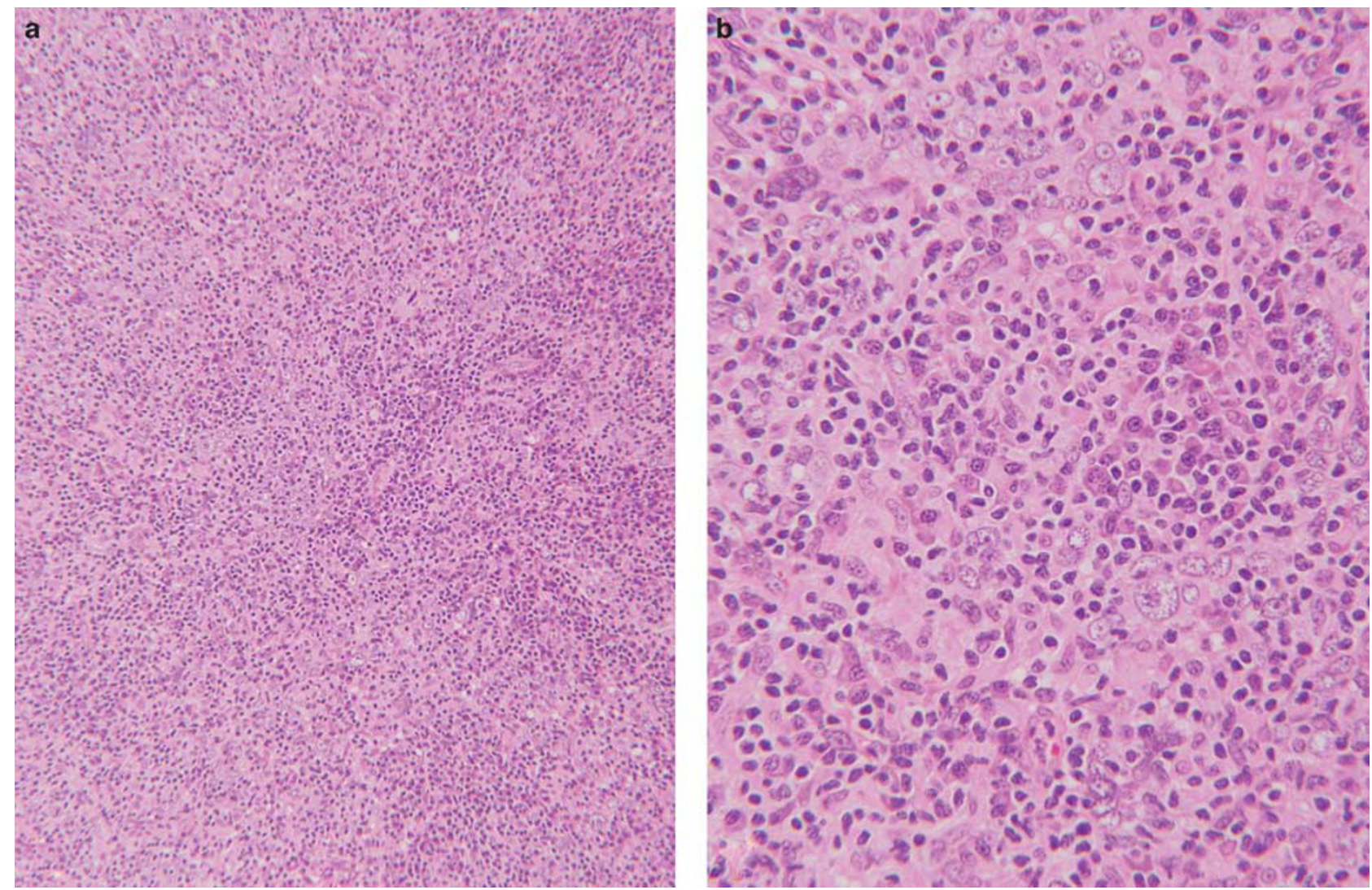

Figure 1 Morphology of undifferentiated (lymphoepithelial) carcinoma of the oropharynx. (a) Low-power view showing sheets of neoplastic cells with ill-defined borders and set in a background of mixed lymphoid tissue (hematoxylin and eosin; $100 \times$ magnification). (b) High-power view showing cells with markedly atypical tumor cells with nuclei with vesicular chromatin and prominent nucleoli (hematoxylin and eosin; $400 \times$ magnification). 

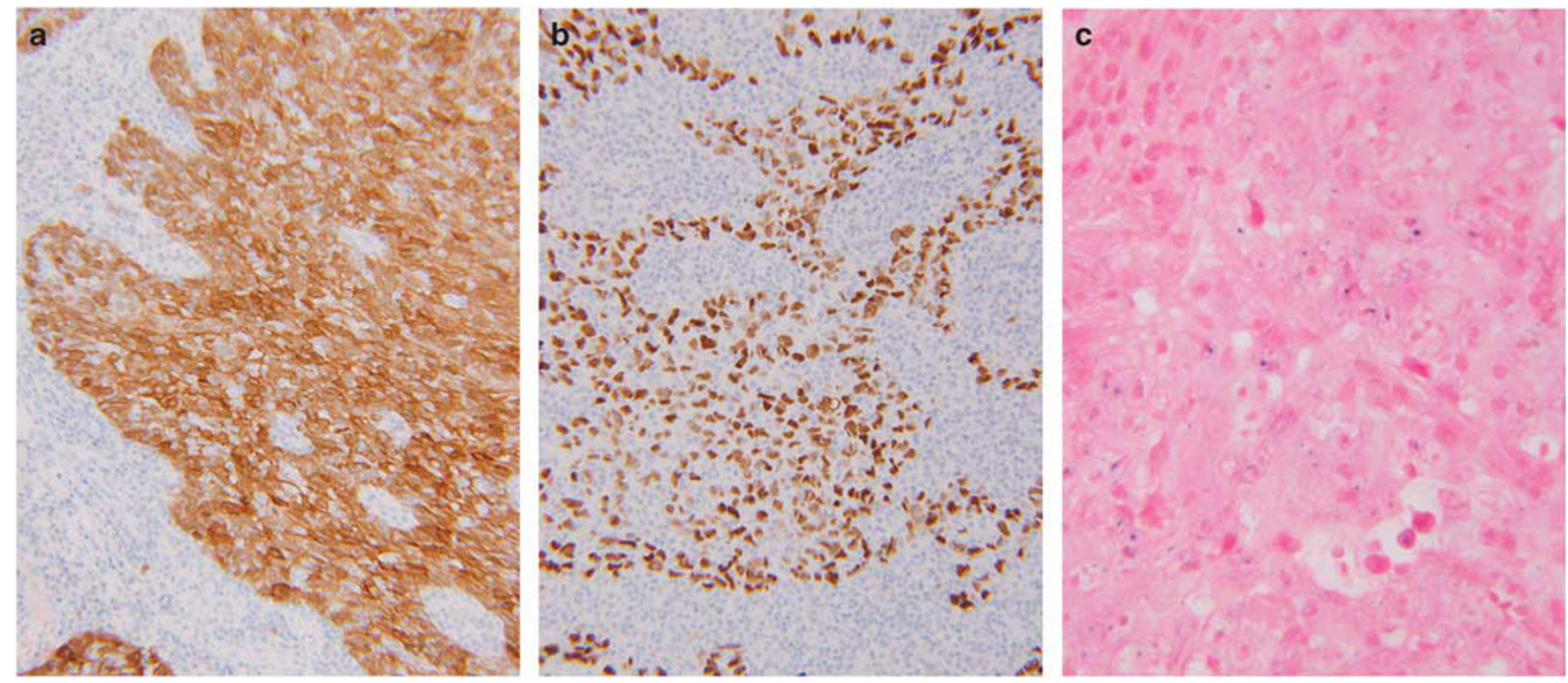

Figure 2 Special staining results in oropharyngeal undifferentiated carcinoma. (a) Immunohistochemistry for p16 showing strong, diffuse cytoplasmic, and nuclear staining $(200 \times$ magnification). (b) Immunohistochemistry for p53 showing strong expression in over $90 \%$ of the tumor cell nuclei $(200 \times$ magnification). (c) In-situ hybridization for high-risk HPV positivity with punctate, blue nuclear staining $(600 \times$ magnification). HPV, human papillomavirus.

and trabeculae of carcinoma intimately intermingled with variable numbers of lymphocytes and plasma cells. Further, the tumors had to have syncytialappearing large tumor cells with indistinct cell borders, round to oval vesicular nuclei, and large central nucleoli; however, sometimes the nuclei could have chromatin-rich rather than vesicular nuclei. ${ }^{2}$ Cases were included only after consensus review and agreement by all three pathologists that the features were diagnostic. Cases were excluded if they had distinguishing characteristics of other tumor types. This included cases that were more discretely nested and less syncytial, which we considered to be (according to our previously characterized histological typing system of oropharyngeal SCC $^{13}$ ) non-keratinizing SCC or non-keratinizing SCC with maturation.

\section{Immunohistochemistry}

Immunohistochemistry was performed for p16 and p53 on representative $4-\mu \mathrm{m}$ sections cut from formalin-fixed, paraffin-embedded tissue on a Ventana Benchmark XT automated immunostainer (Ventana Medical Systems, Tucson, AZ, USA) according to standard protocols and with appropriate positive controls. Antigen retrieval, standard on the machine, used the Ventana CC1, EDTA-Tris, pH 8.0 solution. We used monoclonal antibodies to p16 (MTM Laboratories; 1:1 dilution) and p53 (Ventana Medical Systems; prediluted). The staining pattern for p16 was nuclear and cytoplasmic in all cases and was considered positive if more than $50 \%$ of the tumor cells were reactive. p53 immunostaining was nuclear in all cases and was classified according to the percent positive cells as either negative $(<25 \%$ nuclear staining) or positive $(25 \%$ or greater). This scoring system is based on a concept that cases with greater than $25 \%$ of cells with nuclear staining are more likely to harbor p53 mutations $^{27}$ (Figure 2).

\section{In Situ Hybridization}

In situ hybridization was performed on formalinfixed, paraffin-embedded $4-\mu \mathrm{m}$ tissue sections using for high-risk HPV and for EBV-encoded small RNA (EBER) using an I View Blue Plus Detection Kit (Ventana Medical System). The assays used the Ventana INFORM EBER probe and the Ventana HPV III family 16, probe $\mathrm{B}$, a cocktail recognizing the high-risk HPV (HR HPV) types 16, 18, 31, 33, 35, 45, $51,52,56,58,59,68$, and 70 . Staining was in a totally enclosed system and was performed according to the manufacturer's instructions. Ventana Red Counterstain II (Ventana Medical System) was used. Positive staining was identified as blue nuclear dots. Any definitive nuclear staining in the tumor cells was considered positive. Cases were classified in a binary manner as either positive or negative.

\section{HPV PCR}

Molecular detection of HPV DNA by polymerase chain reaction (PCR) was carried out using $2 \mathrm{~mm}$ cores of formalin-fixed paraffin-embedded tumor identified from the corresponding H\&E slide. These cores were deparaffinized using a series of xylene and ethanol washes. Next, they were subjected to a rigorous proteinase $\mathrm{K}$ digestion with an incubation 
time tailored for recovery of DNA. The methodology for DNA purification included RNase treatment, protein precipitation, and DNA precipitation. PCR was then performed using the INNO-LiPA HPV Genotyping Extra kits. Part of the L1 region of the HPV genome is amplified using SPF10 primers. For high-risk HPV, a 65-bp fragment is amplified. An additional primer pair for the amplification of the human $H L A-D P B 1$ gene is added to monitor sample quality and extraction. For specimens where the HPV amplification product was present on initial reaction, they were hybridized to type-specific probes immobilized as parallel lines on membrane strips pre-made by the manufacturer. After hybridization and stringent washing, streptavidin-conjugated alkaline phosphatase was added. Incubation with BCIP/NBT chromogen yielded a purple precipitate. The results were visually read and compared with the provided interpretation chart to type the HPV.

\section{Results}

A total of 16 cases were identified in our files that met the criteria for undifferentiated carcinoma as described above. These cases were from 1992 to 2009. Clinical and pathological characteristics of the cases are shown in Tables 1 and 2. Patients were predominantly male, the majority smokers (either current or lifetime), and had an average age of 59 years (range 36-81; median 60). In all, 13 of the tumors were from the palatine tonsil $(81 \%)$. The other three were either base of tongue or soft palate. There were only four biopsy cases and 12 surgical resections. Two patients were treated by primary surgery alone, 10 by primary surgery followed by postoperative radiation therapy, and four by primary radiation. Six patients received chemotherapy.

Table 3 shows viral status, immunohistochemical profile, and patient outcome in each case. Tables 4 and 5 summarize the results. Of the 16 cases, 14 $(88 \%)$ were p16 positive with staining in at least $50 \%$ of the tumor cells. One of the remaining two

Table 1 Clinical characteristics of the cases

\begin{tabular}{lc}
\hline Patient characteristics (n) & \% of cases \\
\hline Gender & \\
$\quad$ Male (14) & 88 \\
Female (2) & 12 \\
Tobacco use & \\
Smoker, current or ever (14) & 88 \\
Non-smoker (1) & 6 \\
Unknown (1) & 6 \\
Average age & 59.2 \\
& \\
Treatment type & \\
Surgery alone (2) & 13 \\
Surgery+postoperative IMRT (10) & 63 \\
Primary IMRT (4) & 25 \\
\hline
\end{tabular}

cases had focal, weak staining and the other was completely negative. All 14 of the p16-positive tumors had high-risk HPV either by DNA in situ hybridization or by PCR. Only five tumors were p53 positive ( $>25 \%$ staining and thus presumed to have gene mutation).

The average follow-up was 44.0 months or 3.6 years (range 1.9-136.0 months). Of the 16 patients, three $(19 \%)$ had tumor recurrence, two had regional recurrence only, and an additional patient had local and regional recurrence, as well as distant metastases. Only two of these patients (13\% of the total) died with evidence of disease (which we thus assume as dying of disease). These two patients, age 52 and 62, respectively, died 11.2 and 3.2 years after diagnosis. At last follow-up, seven of 16 (44\%) patients were still alive. For those patients with adequate follow-up, 2-year overall survival was $79 \%$ (11 of 14 patients alive) and disease-specific survival was $100 \%$ (all 14 patients alive or died without evidence of disease). For 11 patients, 3-year overall survival was $55 \%$ (six of 11 patients alive) and disease-specific survival was $100 \%$ (all 11 patients alive or dead without evidence of disease).

\section{Discussion}

Non-nasopharyngeal undifferentiated (lymphoepithelial) carcinomas of the head and neck region are uncommon tumors that occur predominantly in the oropharynx and major salivary glands. There is a very strong association between nasopharyngeal undifferentiated carcinoma and EBV. ${ }^{2}$ However, the literature on the non-oropharyngeal cases shows that in so-called 'endemic' areas such as Southeast Asia and in Eskimo populations they are still

Table 2 Pathological characteristics of the cases

\begin{tabular}{lr}
\hline Tumor characteristics (n) & \% of cases \\
\hline Tumor site & \\
Tonsil (13) & 81 \\
Base of tongue (2) & 13 \\
Soft palate (1) & 6 \\
TNM stage & \\
I (1) & 6 \\
II (2) & 13 \\
III (0) & 0 \\
IV (13) & 81 \\
Tumor stage & \\
T1 (5) & 31 \\
T2 (6) & 38 \\
T3 (4) & 25 \\
T4 (1) & 6 \\
& \\
Lymph-node metastases & 19 \\
Not present-No. (3) & 81 \\
Present (13) & 69 \\
N2 (11) & 13 \\
N3 (2) & \\
\hline
\end{tabular}


Table 3 Test results and clinical outcomes for individual cases

\begin{tabular}{|c|c|c|c|c|c|c|c|}
\hline Case & $H P V$ & p16 & p53 & $E B V(E B E R)$ & Recurrence & Time, in months & Outcome \\
\hline 1 & + & + & - & - & $\mathrm{R}$ & 33 & Alive \\
\hline 2 & + & + & - & - & None & 127 & Dead \\
\hline 3 & + & + & - & - & None & 22 & Alive \\
\hline 4 & + & + & - & - & None & 48 & Dead \\
\hline 5 & + & + & - & - & None & 9 & Dead \\
\hline 6 & + & + & - & - & None & 68 & Alive \\
\hline 7 & + & + & - & - & None & 2 & Alive \\
\hline 8 & + & + & - & - & None & 15 & Dead \\
\hline 9 & + & + & - & - & $\mathrm{L} / \mathrm{R} / \mathrm{D}$ & 136 & Dead \\
\hline 10 & - & + & No tumor & - & None & 27 & Dead \\
\hline 11 & + & + & - & No tumor & $\mathrm{R}$ & 38 & Dead \\
\hline 12 & + & + & + & - & None & 29 & Alive \\
\hline 13 & + & - & + & - & None & 33 & Alive \\
\hline 14 & + & + & + & - & None & 26 & Dead \\
\hline 15 & + & + & + & - & None & 79 & Alive \\
\hline 16 & - & - & + & - & None & 13 & Dead \\
\hline
\end{tabular}

Abbreviations: L, local recurrence; R, regional recurrence; D, distant metastasis; HPV, human papillomavirus; EBV, Epstein Barr virus; EBER, Epstein Barr virus-encoded small RNA.

Table 4 Summary of testing results of the cases

\begin{tabular}{llll}
\hline$p 16$ & HPV status & p53 & EBV status (EBER) \\
\hline Positive: $14(88 \%)$ & Positive: $14(88 \%)$ & Positive: $5(33 \%)$ & Positive: $0(0 \%)$ \\
& ISH+, PCR n/a: 8 & No tumor present: 1 & No tumor remaining: 1 \\
Negative: $2(12 \%)$ & ISH-, PCR+: 6 & Negative: $10(67 \%)$ & Negative: $15(100 \%)$ \\
\hline
\end{tabular}

Abbreviations: HPV, human papillomavirus; ISH, in-situ hybridization; PCR, polymerase chain reaction; EBV, Epstein-Barr virus; EBER, Epstein Barr virus-encoded small RNA.

usually EBV-related, whereas in Western countries, they are typically EBV-negative. ${ }^{7}$ In the current study on oropharyngeal undifferentiated carcinomas, all were EBV-negative. Conversely, almost all cases harbored high-risk HPV as demonstrated by in situ hybridization and/or PCR. These tumors also expressed a molecular profile (ie, high p16 and low p53) characteristic of HPV-related carcinomas. p16 overexpression is considered a surrogate marker of transcriptionally active HPV. It is a tumor suppressor protein that is aberrantly overexpressed when high-risk HPV protein E7 is produced. E7 degrades retinoblastoma protein, which normally serves to suppress p16 transcription. ${ }^{18,28}$

We found that these tumors have essentially the same demographics as other HPV-related/p16 positive oropharyngeal squamous cell carcinoma, being predominantly found in men, an average age of $\sim 60$ years, and most patients being smokers. This latter rate of $88 \%$ may be higher than that for oropharyngeal squamous cell carcinoma in general, which has a significant minority of lifetime non-smokers, however, our sample size is too small to draw any meaningful conclusion. ${ }^{16,29,30}$ Pathological features were similar as well, with most $(\sim 70 \%)$ patients presenting with $\mathrm{T} 1$ or $\mathrm{T} 2$ tumors ${ }^{16,29}$ and most $(\sim 80 \%)$ presenting with cervical lymph-node metastases. ${ }^{31}$ Despite this very high rate of nodal
Table 5 Clinical outcomes of the patients

\begin{tabular}{|c|c|c|}
\hline \multicolumn{2}{|l|}{ Outcome } & \multirow{2}{*}{$\frac{\% \text { of cases }}{19}$} \\
\hline Recurrence (3) & & \\
\hline Local (1) & & 6 \\
\hline Regional (3) & & 19 \\
\hline Distant (1) & & 6 \\
\hline Survival rates ${ }^{\mathrm{a}}$ & 2 year $(\%)$ & 3 year $(\%)$ \\
\hline Overall survival & 79 & 55 \\
\hline Disease-specific survival & 100 & 100 \\
\hline
\end{tabular}

${ }^{\mathrm{a}}$ For patients dying before 2 (or 3 ) years and surviving patients with at least 2 (or 3) years of clinical follow-up, respectively.

metastases, the prognosis was quite favorable. Only three patients developed recurrent disease and only one developed distant metastatic disease. Interestingly, the distant metastasis was 9 years after the initial diagnosis. All of the clinical, pathological, and molecular findings are consistent with an HPV etiology.

All of our cases were negative for EBV, which is consistent with the literature on EBV in oropharyngeal undifferentiated carcinoma in Western patient populations. ${ }^{7}$ A recent study also evaluated 
oropharyngeal undifferentiated (lymphoepithelial) carcinomas for HPV. ${ }^{4}$ It was demonstrated in 19 of their 22 cases $(86 \%)$ by DNA in situ hybridization and all 22 of their cases $(100 \%)$ were also p16 positive. All 22 of their cases were also EBV negative by in situ hybridization for EBER.

It is of interest that our observations are consistent with recent findings that HPV-related oropharyngeal squamous cell carcinoma may present a variety of morphological patterns, yet, essentially always shows favorable clinical outcomes. This has been demonstrated in non-keratinizing, ${ }^{13,14,16}$ basaloid, ${ }^{26,23}$ and papillary squamous cell carcinoma ${ }^{25}$ of the oropharynx, and we have also found it in adenosquamous carcinoma (unpublished data).

In summary, undifferentiated (lymphoepithelial) carcinoma of the oropharynx is almost always associated with biologically active high-risk HPV. Unlike nasopharyngeal undifferentiated carcinoma, when this tumor type occurs in the oropharynx in Western countries, it is not EBV-related, and, despite the alarming histology, these tumors seem to be responsive to therapy and have a favorable prognosis.

\section{Acknowledgements}

We would like to thank Bridgette Sims RN for her help in obtaining clinical information on these patients, and also Walter Clermont for his help in preparing the figures for the manuscript.

\section{Disclosure/conflict of interest}

The authors declare no conflict of interest.

\section{References}

1 Nicholls JM, Agathanggelou A, Fung K, et al The association of squamous cell carcinomas of the nasopharynx with Epstein-Barr virus shows geographical variation reminiscent of Burkitt's lymphoma. J Pathol 1997;183:164-168.

2 Chan JKC, Bray J, McCarron P, et al Nasopharyngeal carcinoma. In: Barnes EL, Eveson JW, Reichart, P Sidranksy D (eds). World Health Organization Classification of Tumours-Pathology and Genetics of Head and Neck Tumours, Vol IARC Press: Geneva, Switzerland, 2005, pp 85-97.

3 Lee AW, Sze WM, Au JS, et al Treatment results for nasopharyngeal carcinoma in the modern era: the Hong Kong experience. Int J Radiat Oncol Biol Phys 2005;61:1107-1116.

4 Singhi AD, Stelow EB, Mills SE, et al Lymphoepithelial-like carcinoma of the oropharynx: a morphologic variant of HPV-related head and neck carcinoma. Am J Surg Pathol 2010;34:800-805.

5 Abdulla AK, Mian MY. Lymphoepithelial carcinoma of salivary glands. Head Neck 1996;18:577-581.

6 Chan JK, Yip TT, Tsang WY, et al Specific association of Epstein-Barr virus with lymphoepithelial carcinoma among tumors and tumorlike lesions of the salivary gland. Arch Pathol Lab Med 1994;118:994-997.

7 Iezzoni JC, Gaffey MJ, Weiss LM. The role of EpsteinBarr virus in lymphoepithelioma-like carcinomas. Am J Clin Pathol 1995;103:308-315.

8 Frank DK, Cheron F, Cho H, et al Nonnasopharyngeal lymphoepitheliomas (undifferentiated carcinomas) of the upper aerodigestive tract. Ann Otol Rhinol Laryngol 1995;104:305-310.

9 Sckolnick J, Murphy J, Hunt JL. Microsatellite instability in nasopharyngeal and lymphoepithelial carcinomas of the head and neck. Am J Surg Pathol 2006;30:1250-1253.

10 Wang CP, Chang YL, Ko JY, et al Lymphoepithelial carcinoma versus large cell undifferentiated carcinoma of the major salivary glands. Cancer 2004;101: 2020-2027.

11 Vasef MA, Ferlito A, Weiss LM. Nasopharyngeal carcinoma, with emphasis on its relationship to EpsteinBarr virus. Ann Otol Rhinol Laryngol 1997;106:348-356.

12 Tsai ST, Jin YT, Su IJ. Expression of EBER1 in primary and metastatic nasopharyngeal carcinoma tissues using in situ hybridization. A correlation with WHO histologic subtypes. Cancer 1996;77:231-236.

13 Chernock RD, El-Mofty SK, Thorstad WL, et al HPVrelated nonkeratinizing squamous cell carcinoma of the oropharynx: utility of microscopic features in predicting patient outcome. Head Neck Pathol 2009; 3:186-194.

14 El-Mofty SK, Patil S. Human papillomavirus (HPV)related oropharyngeal nonkeratinizing squamous cell carcinoma: characterization of a distinct phenotype. Oral Surg Oral Med Oral Pathol Oral Radiol Endod 2006;101:339-345.

15 Wilczynski SP, Lin BT, Xie Y, et al Detection of human papillomavirus DNA and oncoprotein overexpression are associated with distinct morphological patterns of tonsillar squamous cell carcinoma. Am J Pathol 1998; 152:145-156.

16 Lewis Jr JS, Thorstad WL, Chernock RD, et al p16 positive oropharyngeal squamous cell carcinoma: an entity with a favorable prognosis regardless of tumor HPV status. Am J Surg Pathol 2010;34:1088-1096.

17 Dai M. Human papillomavirus type 16 and TP53 Mutation in oral cancer: matched analysis of the IARC multicenter study. Cancer Res 2004;64:468-471.

18 Adelstein DJ, Ridge JA, Gillison ML, et al Head and neck squamous cell cancer and the human papillomavirus: summary of a National Cancer Institute State of the Science Meeting, November 9-10, 2008, Washington, D.C. Head Neck 2009;31:1393-1422.

19 Fakhry C, Westra WH, Li S, et al Improved survival of patients with human papillomavirus-positive head and neck squamous cell carcinoma in a prospective clinical trial. J Natl Cancer Inst 2008;100:261-269.

20 Hording U, Teglbjaerg CS, Visfeldt J, et al Human papillomavirus types 16 and 18 in adenocarcinoma of the uterine cervix. Gynecol Oncol 1992;46:313-316.

21 Noel J, Lespagnard L, Fayt I, et al Evidence of human papilloma virus infection but lack of Epstein-Barr virus in lymphoepithelioma-like carcinoma of uterine cervix: report of two cases and review of the literature. Hum Pathol 2001;32:135-138.

22 Teshima H, Beaudenon S, Koi S, et al Human papillomavirus type 18 DNA sequences in adenocarcinoma and adenosquamous carcinoma of the uterine cervix. Arch Gynecol Obstet 1997;259:169-177. 
23 Chernock RD, Lewis Jr JS, Zhang Q, et al Human papillomavirus-positive basaloid squamous cell carcinomas of the upper aerodigestive tract: a distinct clinicopathologic and molecular subtype of basaloid squamous cell carcinoma. Hum Pathol 2010;41: 1016-1023.

24 Keelawat S, Liu CZ, Roehm PC, et al Adenosquamous carcinoma of the upper aerodigestive tract: a clinicopathologic study of 12 cases and review of the literature. Am J Otolaryngol 2002;23:160-168.

25 Jo VY, Mills SE, Stoler MH, et al Papillary squamous cell carcinoma of the head and neck: frequent association with human papillomavirus infection and invasive carcinoma. Am J Surg Pathol 2009;33: 1720-1724.

26 Begum S, Westra WH. Basaloid squamous cell carcinoma of the head and neck is a mixed variant that can be further resolved by HPV status. Am J Surg Pathol 2008;32:1044-1050.
27 Cruz I, Snijders PJ, Van Houten V, et al Specific p53 immunostaining patterns are associated with smoking habits in patients with oral squamous cell carcinomas. J Clin Pathol 2002;55:834-840.

28 Weinberger PM, Yu Z, Haffty BG, et al Prognostic significance of p16 protein levels in oropharyngeal squamous cell cancer. Clin Cancer Res 2004;10: 5684-5691.

29 Hafkamp HC, Manni JJ, Haesevoets A, et al Marked differences in survival rate between smokers and nonsmokers with HPV 16-associated tonsillar carcinomas. Int J Cancer 2008;122:2656-2664.

30 Ang KK, Harris J, Wheeler R, et al Human papillomavirus and survival of patients with oropharyngeal cancer. N Engl J Med 2010;363:24-35.

31 Woolgar JA. The topography of cervical lymph node metastases revisited: the histological findings in 526 sides of neck dissection from 439 previously untreated patients. Int J Oral Maxillofac Surg 2007;36:219-225. 